\title{
Health Hazards of Food Additives
}

\author{
Deepa Indoria*
}

Krishi Vigyan Kendra, Chittorgarh, MPUAT, Udaipur, India

*Corresponding author

\section{A B S T R A C T}

\section{Keywords}

Food additives, Preserve flavour, Processed foods

\section{Article Info}

Accepted:

18 March 2020

Available Online:

10 April 2020
Food additives are substances added to food to preserve flavour or enhance its taste, appearance, or other qualities. Some additives have been used for centuries; for example, preserving food by pickling (with vinegar), salting, as with bacon, preserving sweets or using sulphur dioxide as with wines. With the advent of processed foods in the second half of the twentieth century, many more additives have been introduced, of both natural and artificial origin. Food additives also include substances that may be introduced to food indirectly (called "indirect additives") in the manufacturing process, through packaging, or during storage or transport.

\section{Sodium nitrate}

Sodium nitrate is added to processed meats to stop bacterial growth1.The major acute toxic effect of nitrate and nitrite poisoning is methemoglobinemia. Ingested nitrate or nitrite under conditions that result in endogenous nitrosation is probably carcinogenic to humans (group2A2). In a study conducted by Hamdy and co-workers sub chronic exposure of rats to sodium nitrate resulted in testicular toxicity as evidenced by decreased sperm count and motility, daily sperm production and testis weight, inhibited activity of enzyme markers of spermatogenesis and induction of histopathological changes 3 .

\section{Sulphites}

Sulphites are widely used as preservative and antioxidant additives in the food and pharmaceutical industries. Exposure to sulphites has been reported to induce a range of adverse clinical effects in sensitive individuals, ranging from dermatitis, urticaria, flushing, hypotension, abdominal pain and diarrhoea to life threatening anaphylactic and asthmatic reactions. Exposure to the sulphites arises mainly from the consumption of foods and drinks that contain these additives. Exposure may also occur through the use of 
pharmaceutical products, as well as in occupational settings. Most studies report a prevalence of sulphite sensitivity of 3 to $10 \%$ among asthmatic subjects who ingest these additives. The severity of these reactions varies, and steroid-dependent asthmatics, those with marked airway hyper responsiveness, and children with chronic asthma, appear to be at greater risk4.

\section{Azodicarbonamide}

Azodicarbonamide (ADA) is used as a whitening agent in cereal flour and as a dough conditioner in bread baking. It is claimed to be a skin irritant in man. Occupational exposure has been associated with irritation of the eyes and respiratory tract, asthmatic lung reactions, reduced lung function, and allergic dermatitis. In rats and mice, acute oral toxicity was low, and a single injection of ADA produced central nervous system depression in mice. In rats, some evidence of a weak antithyroid action was seen on repeated oral exposure. ADA generally displayed a low toxic potential in rats and mice following repeated inhalational though findings in the lungs of rats may have indicated an effect on the immune system. Repeated inhalations of ADA did not cause sperm abnormalities in rats and mice, although it may have induced chromosome damage in mice injected intraperitoneally and in mammalian cells in culture.

ADA did not produce heritable mutations in fruit flies but it was mutagenic in bacterial tests5.During bread making, ADA completely breaks down to form other chemicals, one of which is semicarbazide (SEM).

At high levels, SEM has been shown to increase the incident of tumors when fed to female mice, but not to male mice or either gender of rat. These studies were conducted innrodents at levels of SEM that far exceed estimates of human exposure from the consumption of ADA-treated flour or bread products6.

\section{Potassium bromate}

Potassium bromate (KBrO3) is widely used as a food additive and is a major water disinfection by-product. The study conducted by Altoom and co-workers reports the side effects of $\mathrm{KBrO}_{3}$ administration in Swiss mice. Animals were randomly divided into three groups: control, low dose

$\mathrm{KBrO}_{3}(100 \mathrm{mg} / \mathrm{kg} /$ day $)$ and high dose $\mathrm{KBrO}_{3}$ (200 mg/kg/day) groups. Administration of $\mathrm{KBrO} 3$ led to decreased white blood corpuscles, red blood corpuscles and platelets count in the animals of both the high and the low dose groups. Altered lipid profile represented as low density lipoprotein (LDL), high density lipoprotein (HDL) and cholesterol levels were observed in plasma samples of both $\mathrm{KBrO}_{3}$ treated groups of mice. An increased plasma level of LDH was detected in both $\mathrm{KBrO}_{3}$ treated groups. Histological investigations showed impaired renal and hepatic histology that was concomitant with increased plasma creatinine level in both of $\mathrm{KBrO}_{3}$ - treated groups.

Decreased glutathione level in both renal and hepatic tissue of mice after $\mathrm{KBrO}_{3}$ intake was detected7.The agent is carcinogenic in rats and nephro toxic in both man and experimental animals when given orally. It has been demonstrated that $\mathrm{KBrO}_{3}$ induces renal cell tumours, mesotheliomas of the peritoneum, and follicular cell tumours of the thyroid in rats.

Experiments aimed at elucidating the mode of carcinogenic action have revealed that $\mathrm{KBrO}_{3}$ is a complete carcinogen, possessing both initiating and promoting activities for rat renal tumorigenesis. 


\section{BHA and BHT}

The primary use for butylated hydroxyanisole (BHA) is as an antioxidant and preservative in food, food packaging, animal feed, and cosmetics; rubber and petroleum products as well. Although BHA is not an irritant, it can cause skin reactions owing to its weak allergic sensitization potential (allergic contact dermatitis). The agent is possibly carcinogenic to humans (group 2B9). Butylated hydroxytoluene (BHT) is also used as antioxidant and preservative in food and cosmetics. It was reported that but can cause allergic reactions (few cases). It is possibly carcinogenic to humans. It is possibly hormonal disruptor in humans. It may act as xenoestrogen and disrupt testicular development in rats. It has postnatal developmental effects in rats and mice.

\section{Propylene glycol}

Propylene glycol (PG) is a commonly used solvent for oral, intravenous, and topical pharmaceutical agents. It also thickens dairy products and salad dressing. Although PG is generally considered safe, when used in high doses or for prolonged periods, PG toxicity can occur. Reported adverse effects from PG include central nervous system toxicity, hyper osmolarity, haemolysis, cardiac arrhythmia, seizures, agitation, and lactic acidosis. Patients at risk for toxicity include infants, those with renal or hepatic insufficiency, epilepsy, and burn patients receiving extensive dermal applications of PG containing products.

\section{Monosodium glutamate}

Monosodium Glutamate (MSG) is one of the most widely used food-additives in commercial foods. Its application has increased over time and it is found in many different ingredients and processed foods obtainable in every market or grocery store. MSG gives a special aroma to processed foods which is known as umami in Japanese. This taste sensation is also called savoury. In many countries MSG goes by the name China salt. Beside its flavour enhancing effects, MSG has been associated with various forms of toxicity. It has been linked with obesity, metabolic disorders, Chinese restaurant syndrome (MSG symptom complex: headache, skin flushing, and sweating), neurotoxic effects and detrimental effects on the reproductive organs.

\section{Recombinant bovine growth hormone}

Recombinant bovine growth hormone (rBGH) is a synthetic hormone that is marketed to dairy farmers to increase milk production in cows. It has been used in the United States since it was approved by the Food and Drug Administration in 1993, but its use is not permitted in the European Union, Canada, and some other countries. The evidence for potential harm of $\mathrm{rBGH}$ to humans is inconclusive. It is not clear that drinking milk produced using $\mathrm{rBGH}$ significantly increases IGF-1 (insulin-like growth factor) levels in humans or adds to the risk of developing cancer. The increased use of antibiotics to treat $\mathrm{rBGH}$-induced mastitis does promote the development of antibiotic-resistant bacteria.

\section{Refined vegetable oil}

These include soybean oil, corn oil, safflower oil, canola oil, and peanut oil. Refined vegetable oil is high in omega-6 fats, which are thought to cause heart disease and cancer1. Results of the study conducted by Venkata and Subramanyam confirm that the thermal oxidation of cooking oil (repeatedly heated vegetable oil) generates free radicals and dietary consumption of such oil results in detrimental health effects, such as oxidative stress, Genotoxic and pre neoplastic changes. 


\section{Sodium benzoate}

Sodium benzoate is used as food preservative, antiseptic, medicine, in tobacco, in pharmaceutical preparations, as intermediate for manufacture of dyes, and as a rust and mildew inhibitor. In a study with 2045 patients of dermatological clinics, only 5 persons (approximately 0.2\%) showed a positive reaction in patch tests, while 34 of 5202 patients (approximately 0.7\%) with contact urticaria reacted positively.

Cases of urticaria, asthma, rhinitis, or anaphylactic shock have been reported following oral, dermal, or inhalation exposure to sodium benzoate. The symptoms appear shortly exposure and disappear within a few hours. In human embryonic lung cells treated with sodium benzoate both chromosome abnormalities and mitotic indices were within normal values. Sodium benzoate was mutagenic and cytotoxic in lymphocytes, where it caused micronucleus formation and chromosome break.

\section{Brominated vegetable oil}

Brominates vegetable oil (BVO) is a synthetic chemical that is created when vegetable oil is bonded to the element bromine. Bromine is heavy, and it keeps the oil from floating to the top of water-based solutions, like soft drinks. In very high amounts drunk over a long period of time, BVO can build up in the body and cause toxic effects. Signs and symptoms reported in cases of high BVO ingestion through drinks are headaches, fatigue, loss of muscle coordination and memory, bromoderma and halogen acne.

\section{Propyl gallate}

Propyl gallate is used as an antioxidant for foods and cosmetics; especially fats, oils, emulsions, and waxes. It is used in transformer oils and as a stabilizer for synthetic vitamin A. It is also used as experimental medication. It has been reported statistically significant increase in propyl gallate-positive rates on patch testing over the last decade. Propylgallate produced contact dermatitis in 5 of 10 patients tested. Propyl gallate was investigated in vitro at concentration of $0.5,5.0$ and $50 \mathrm{ug} / \mathrm{mL}$ employing WI-38 human embryonic lung 6 cells for anaphase abnormalities and it was not mutagenic.

\section{Chlorine dioxide}

Chlorine dioxide is used in bleaching cellulose, paper-pulp, flour, leather, fats and oils, textiles, and beeswax. It is also used for purification of water, taste and odour control of water, cleaning and detanning leather, in the manufacture of chloride salts, and as an oxidizing agent, bactericide, antiseptic and deodorizer. Potential symptoms of over exposure (including occupational exposure) are irritation of eyes, nose, and throat, as well as coughing, wheezing, bronchitis, and pulmonary oedema.

Workers acutely exposed to chlorine dioxide developed both reactive airways dysfunction syndrome, a form of occupational asthma, and an upper airways reactive disorder that was called reactive upper airways dysfunction syndrome.

A positive association was found between exposure of the mother to chlorine dioxide treated water during pregnancy and prematurity of the new born.

Children born of mothers who drank disinfected water treated with either chlorine dioxide or hypochlorite were noted to have an increased incidence of small cranial circumference, small body length, and neonatal jaundice. Chlorine dioxide was found to be weakly genotoxic in human leukocytes18. 


\section{Parabens}

Para bens are a series of compounds used as a classic antimicrobial preservative in foods, drugs and cosmetics for over 60 years. Para bens are absorbed through the skin and from the gastrointestinal tract, further hydrolyzed to hydroxyl benzoic acid, conjugated and then rapidly excreted in the urine. Recent literature suggested that the mechanism of cytotoxic action of Para bens might be linked to mitochondrial failure dependent on induction of membrane permeability transition accompanied by the mitochondrial depolarization and depletion of cellular ATP through uncoupling of oxidative phosphorylation. Para bens were reported to cause contact dermatitis reactions in some individuals on cutaneous exposure. Para bens have been implicated in numerous cases of contact sensitivity related to cutaneous exposure and as endocrine disruptors 19. Parabens have week estrogenic activity and have been shown to induce the growth of MCF-7 human breast cancer cells in vitro, leading some researchers to suggest their potential as initiators or promoters of breast cancer 20.

\section{Aluminum}

Aluminum is used as a preservative in some packaged foods1. Occupational exposure to aluminium can lead to coughing and decreased performance on neurological tests. Oral exposure to aluminium is usually not harmful. Some studies show that people exposed to high levels of aluminium may develop Alzheimer's disease, but other studies have not found this to be true. Some people who have kidney disease store a lot of aluminum in their bodies. The kidney disease causes less aluminum to be excreted in the urine. Sometimes, these people developed bone or brain diseases that some researchers considered that were caused by the excess aluminum. Brain and bone disease caused by high levels of aluminum in the body have been seen in children with kidney disease. Bone disease has also been seen in children taking some medicines containing aluminum. In these children, the bone damage is caused by aluminium in the stomach preventing the absorption of phosphate. Aluminium is found in breast milk, but only a small amount of this aluminium will enter the infant's body through breastfeeding 21 .

\section{Saccharin}

Saccharin is an artificial sweetener. The Working Group concluded that sodium saccharin produced urothelial bladder tumours in rats by a non-DNA reactive mechanism that involves the formation of a urinary calcium phosphate containing precipitate, cyto toxicity and enhanced cell proliferation. The mechanism is not relative to humans because of critical interspecies differences in urine composition. Saccharin and its salts are not classifiable as to the carcinogenicity to humans (Group 322).

\section{Aspartame}

Aspartame is artificial sweetener. Excess intake of aspartame can cause dizziness, headaches, blurred vision and stomach problems1. Though research into a possible link between aspartame and cancer continues,

\section{T-Butylhydroquinone}

T-Butylhydroquinone (TBHQ) is used as an antioxidant in fats and oils. There have been reports of vision disturbances in individuals exposed to this chemical. TBHQ produced single strand DNA breaks in human cells. Acute neurotoxic effects of animals exposed to TBHQ included convulsions and medullary paralysis. There are no evidences for carcinogenicity so far. 


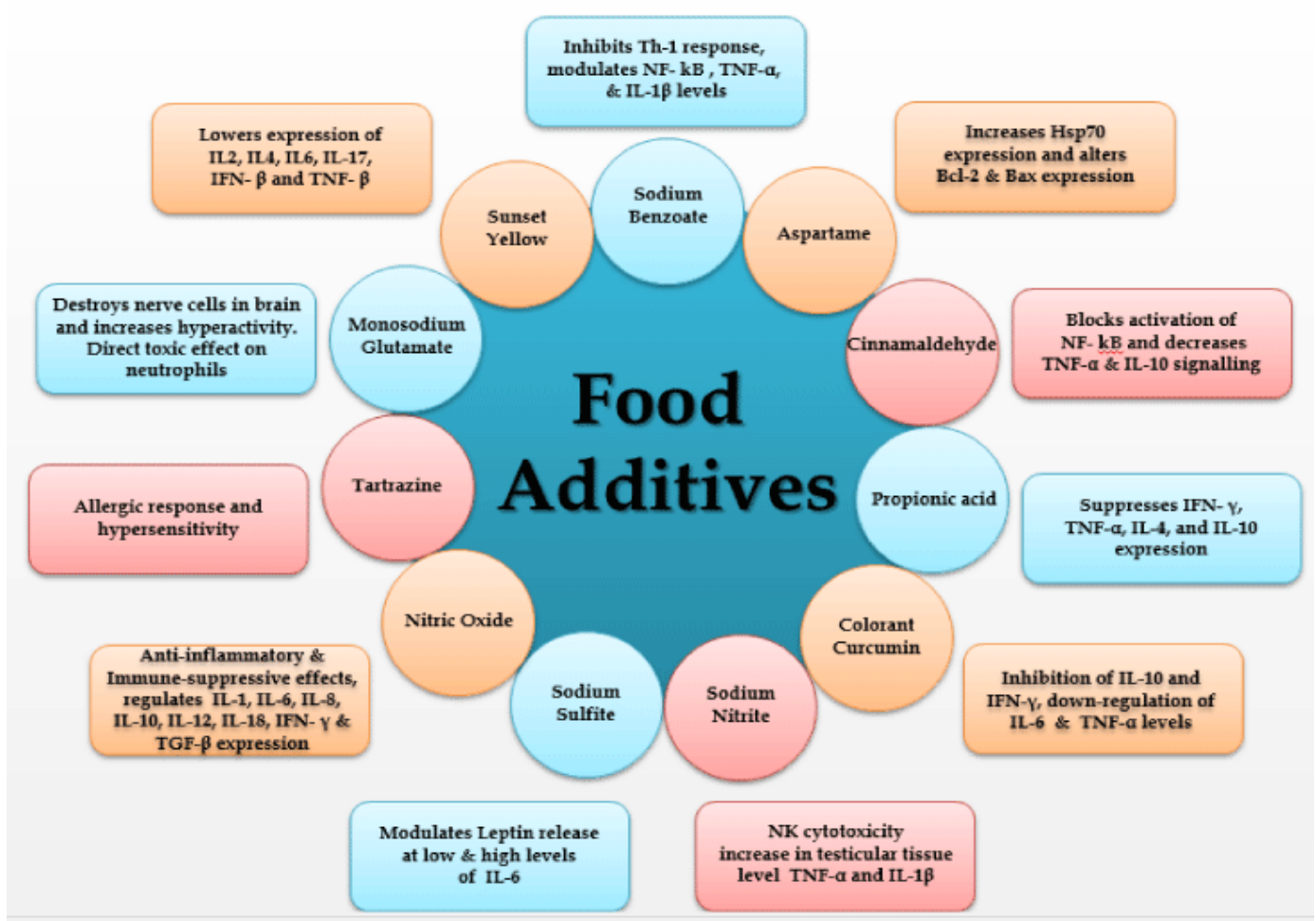

Fig.1

Food Additives: Uses \& Health Concerns

\begin{tabular}{|c|c|c|}
\hline Chemical & Food-Related Use & Selected Health Concerns \\
\hline Bisphenol A (BPA) & $\begin{array}{l}\text { Hardens plastic containers } \\
\text { Prevents rust on metal food and } \\
\text { beverage cans }\end{array}$ & $\begin{array}{l}\text { - Can act like estrogen in the body } \\
\text { and may change the timing of } \\
\text { puberty, decrease fertility, } \\
\text { increase body fat, and possibly } \\
\text { affect the nervous and immune } \\
\text { systems }\end{array}$ \\
\hline Phthalates & $\begin{array}{l}\text { - Makes plastic and vinyl flexible } \\
\text { for use in plastic tubing } \\
\text { Used in industrial food } \\
\text { production }\end{array}$ & $\begin{array}{l}\text { Can affect male genital } \\
\text { development increase childhood } \\
\text { obesity and metabolic function, } \\
\text { and may affect the cardiovascular } \\
\text { system }\end{array}$ \\
\hline $\begin{array}{l}\text { Perfluoroalkyl } \\
\text { chemicals (PFCs) }\end{array}$ & $\begin{array}{l}\text { Creates grease-proof paper and } \\
\text { cardboard in food packaging }\end{array}$ & $\begin{array}{l}\text { - Can reduce immune response, } \\
\text { birth weight, and fertility } \\
\text { May also cause changes to the } \\
\text { thyroid hormone system, which is } \\
\text { crucial for metabolism, digestion, } \\
\text { muscle control, brain } \\
\text { development, and bone strength }\end{array}$ \\
\hline Perchlorate & $\begin{array}{l}\text { - Controls static electricity in } \\
\text { some dry food packaging }\end{array}$ & $\begin{array}{l}\text { May interfere with thyroid } \\
\text { hormone, affecting early life brain } \\
\text { development and growth }\end{array}$ \\
\hline $\begin{array}{l}\text { Synthetic artificial } \\
\text { food colors (AFCs) }\end{array}$ & $\begin{array}{l}\text { - Helps improve the appearance } \\
\text { of processed foods and } \\
\text { beverages- common in } \\
\text { children's food products }\end{array}$ & $\begin{array}{l}\text { Can sometimes act as substitute } \\
\text { for nutritious ingredients, such as } \\
\text { in fruit juice drinks that contain } \\
\text { little or no actual fruit } \\
\text { May have effects on child } \\
\text { behavior and attention }\end{array}$ \\
\hline Nitrates/nitrites & $\begin{array}{l}\text { Preservative and color } \\
\text { enhancer-especially to cured } \\
\text { and processed meats, fish, and } \\
\text { cheese }\end{array}$ & $\begin{array}{l}\text { Linked with tumors in the } \\
\text { digestive and nervous system, as } \\
\text { well as thyroid problems } \\
\text { Can cause methemoglobinemia in } \\
\text { infants and toddlers } \\
\text { Can interfere with the blood's } \\
\text { ability to deliver oxygen in the } \\
\text { body }\end{array}$ \\
\hline
\end{tabular}

Fig.2 


\section{Food dyes}

Red 3 causes cancer in animals. Three dyes (Red 40, Yellow 5, Yellow 6) have been found to be contaminated with benzidine or other carcinogens. At least four dyes (Blue 1, Red 40, Yellow 5, Yellow 6) cause hypersensitivity reactions. Numerous microbiological and rodent studies of Yellow 5 were positive for genotoxicity. Toxicity tests on two dyes (Citrus Red 2 and Orange B) also suggest safety concerns. The inadequacy of much of the testing and the evidence for carcinogenicity, genotoxicity, and hypersensitivity, coupled with the fact that dyes do not improve the safety or nutritional quality of foods, indicates that all of the currently used dyes should be removed from the food supply and replaced, if at all, by safer colorings 29 . Some safety concerns were also reported for Blue 2, Citrus Red 1, Green 3, Red 2, caramel coloring, Brown HT, Orange B, bixin, norbixin and annatto1, but the evidence is scarce.

\section{References}

1. Jawdroppingly Toxic Food Ingredients \& Artificial Additives to Avoid. Public Health Analysis. Retrieved from (on November 20 , 2019) https://mphprogramslist.com/50jawdroppinglytoxic- food-additives-toavoid/

2. Sodium Nitrate. Toxnet. Retrieved from (on November 20, 2019) https://toxnet.nlm.nih.gov/cgibin/ sis/search/a?dbs+hsdb:@term+@DOC $\mathrm{NO}+726$

3. Aly, Hamdy \& Mansour, Ahmed \& AboSalem, Osama \& Abd-Ellah, Hala \& Abdel-Naim, Ashraf. Potential testicular toxicity of sodium nitrate in adult rats. Food and chemical toxicology: an international journal published for the British Industrial Biological Research
Association. 2009:48. 572-8. 10.1016/j.fct.2009.11.034.

4. Vally H, Misso NL. Adverse reactions to the sulphite additives. Gastroenterol Hepatol Bed Bench. 2012; 5(1): 16-23.

5. Toxicity profile for azodicarbonamide. Bibra toxicology advice \& consulting. 1990. Retrieved from https://www.bibrainformation. co.uk/downloads/toxicity-profileforazodicarbonamide- 1990/

6. Azodicarbonamide (ADA) Frequently Asked Questions. FDA. April 1, 2018. Retrieved from https://www.fda.gov/food/foodadditivespetitions/ azodicarbonamideada-frequently-askedquestions

7. Altoom NG, Ajarem J, Allam AA, et al. Deleterious effects of potassium bromate administration on renal and hepatic tissues of Swiss mice. Saudi Journal of Biological Sciences 2018; 25(2): 278-284.

8. Kurokawa Y, Maekawa A, Takahashi M, Hayashi Y. Toxicity and carcinogenicity of potassium bromate-a new renal carcinogen. Environ Health Perspect. 1990; 87: 309-335.

9. Butylated hydroxyanisole. Toxnet. Retrieved from (on November 21, 2019) https://toxnet.nlm.nih.gov/cgibin/ sis/search/a?dbs+hsdb:@term+@DOC $\mathrm{NO}+3913$

10. Analysis of the most appropriate risk management option (RMOA). Anses. 2016:1-48. Retrieved from https://echa.europa.eu/documents/10162 1562a6691-9917- f654-be5a0bf3b0ba5e44 11. Lim TY, Poole RL, Pageler NM. Propylene glycol toxicity in children. $J$ Pediatr Pharmacol Ther. 2014; 19(4):277-282.

12. Niaz K, Zaplatic E, Spoor J. Extensive use of monosodium glutamate: A threat to public health? EXCLI J. 2018; 17: 273278. 
13. Recombinant Bovine Growth Hormone. American Cancer Society. September 10, 2014. Retrieved from https://www.cancer.org/cancer/cancerca uses/ recombinant-bovine-growthhormone.html

14. Perumalla Venkata R, Subramanyam R. Evaluation of the deleterious health effects of consumption of repeatedly heated vegetable oil. Toxicol Rep. 2016; 3: 636-643.
15. Sodium benzoate. Toxnet. Retrieved from (on November 21, 2019) https://toxnet.nlm.nih.gov/cgibin/ sis/search/a?dbs+hsdb:@term+@DOC $\mathrm{NO}+696$

16. Goodman B. Brominated Vegetable Oil. WebMD. Retrieved from (on November 21, 2019) https://www.webmd.com/ foodrecipes/ news/20130129/ brominated-vegetable-oil-qa\#2

\section{How to cite this article:}

Deepa Indoria. 2020. Health Hazards of Food Additives. Int.J.Curr.Microbiol.App.Sci. 9(04): 2374-2381. doi: https://doi.org/10.20546/ijcmas.2020.904.285 